\title{
O público e o privado na gestão da inovação no Brasil
}

\author{
Public and Private in innovative management in Brazil
}

1 Vitor Barletta Machado vitorbmach@yahoo.com.br

2 Agamemnom Rocha Souza

1 PUC-Campinas.

2 Centro Universitário de Volta Redonda, UniFOA.

\section{Resumo}

É ponto constatado por diferentes trabalhos que, no Brasil, os maiores investimentos em pesquisas que geram inovação são feitos pelas universidades públicas, com capital estatal. Verifica-se no comportamento das empresas que investem em pesquisa e desenvolvimento uma busca por se instalarem nas regiões que contam com a presença desses centros universitários, com alta concentração de profissionais qualificados. 0 presente artigo apresenta algumas reflexões sobre essa questão, por meio de estudos de alguns autores clássicos para o pensamento social brasileiro. O objetivo é destacar certa continuidade histórica de mistura da esfera pública e privada na gestão política e econômica de nossa sociedade, em um processo no qual os gastos continuam sendo socializados, enquanto os lucros são apropriados pelos grupos detentores do capital.

\section{Palavras-chave}

Inovação; público e privado; pesquisa e desenvolvimento; universidades; sociologia.

\begin{abstract}
It is a common view for different studies that in Brazil the largest investments in research that generates innovation are made by public universities, with state capital. Even the companies that invest in research and development try to settle in regions that count with the presence of these universities, with high concentration of skilled professionals. This article presents some reflections on this issue through some classic authors from Brazilian social thought. The aim is to highlight some historical continuity concerning the blending of public and private sphere in the political and economic management of Brazilian society, a process in which the expenses are still being socialized while the profits are funneled to the groups that hold the capital.
\end{abstract}

\section{Keywords}

Innovation; public and private; research and development; universities; sociology

\section{Como você deve citar?}

MACHADO, Vitor Barletta; SOUZA, Agamemnom Rocha. O público e o privado na gestão da inovação no Brasil. Cadernos UniFOA, Volta Redonda, n. 30, p. 69-81, abr., 2016. 


\title{
1 INOVADORES
}

As reflexões sobre a questão da inovação no Brasil enfocam, frequentemente, o tema dos avanços tecnológicos e seus impactos no mercado e têm sido realizadas por profissionais de diferentes áreas, mas, principalmente, por economistas, cientistas sociais e administradores, que destacam aspectos diferentes da mesma. Se formos nos concentrar apenas em seu significado imediato, a palavra indicaria tão somente a produção de algo novo, uma resposta genérica que não é satisfatória para os nossos objetivos. Este artigo pretende mostrar como a questão é tratada pelos pesquisadores das três áreas em destaque, para avançar na indicação das especificidades da reflexão sociológica.

Inicio com os autores que se preocuparam diretamente com a questão da gestão de empresas, destacando algumas reflexões que parecem seguir uma direção comum. Em ambiente empresarial, voltado para a colocação de produtos no mercado, o conceito de inovação aparece muito claramente relacionado com o desenvolvimento de um novo produto ou de uma nova maneira de produzir um antigo produto, mas que tenha um resultado econômico positivo, ou seja, para ser inovação uma nova ideia precisa gerar lucro, caso contrário terá sido apenas mais uma ideia ou invenção. Vejamos as seguintes observações de Drucker:

\begin{abstract}
We have again entered an era of innovation, and it is by no means confined to "high tech" or to technology generally. In fact, social innovation - as this book tries to make clear - may be of greater importance and have much greater impact than any scientific or technical invention. (DRUCKER, 2009, p. 219).
\end{abstract}

Because its purpose is to create a customer, the business enterprise has two-and only these two-basic functions: marketing and innovation. [...]

The second function of a business is, therefore, innovation-the provision of different economic satisfactions. It is not enough for the business to provide just any economic goods and services; it must provide better and more economic ones. It is not necessary for a business to grow bigger; but it is necessary that it constantly grow better.

Innovation may result in a lower price-the datum with which the economist has been most concerned, for the simple reason that it is the only one that can be handled by quantitative tools. But the result may also be a new and better product, a new convenience, or the definition of a new want. (Id., 2007, p. 16-17) ${ }^{3}$

Antes de comentarmos as passagens anteriores, vejamos mais duas citações de autores que lidam com o tema, Simantob e Bergerman:

\begin{abstract}
Muita gente fala de inovação pensando em um ambiente caótico, em ideias fortuitas. [...] Sem dúvida, há a possibilidade de ser ocasional. Mas, se a empresa induzir, provocar isso, ela acabará criando um fluxo permanente de ideias. Ora, as empresas inovadoras são exatamente aquelas que conseguem construir um grande estoque de ideias, mesmo que sejam ideias brutas. Sempre chega o momento em que parte dessas ideias brutas começa a ser testada. Depois, parte das ideias testadas acaba, naturalmente, tornando-se protótipo ou iniciativa. Por fim, um número pequeno desses protótipos e iniciativas se transforma em produtos, serviços ou novas estratégias que agregam valor à organização. Eis aí a inovação. (SIMANTOB, 2006b).
\end{abstract}

Definida no Dicionário Houaiss como "aquilo que é novo, coisa nova, novidade", na prática do mercado inovação é "a introdução no mercado de um novo produto ou processo, ou de uma versão melhorada de um produto ou processo existente". Em outras palavras, inovação é sinônimo de geração de riqueza para um país, sua sociedade e suas entidades privadas e públicas. (BERGERMAN, 2005, p. 1333).

3 "Entramos novamente em uma era de inovação, e é de modo algum confinada ao "high tech" ou tecnologia em geral. Na verdade, a inovação social - como este livro tenta deixar claro - pode ser de maior importância e ter um impacto muito maior do que qualquer invenção científica ou técnica. (DRUCKER, 2009, p. 219).

Porque o seu objetivo é criar um cliente, a empresa de negócios tem duas - e apenas estas duas - funções básicas: marketing e inovação. [...]

A segunda função de um negócio é, portanto, a inovação, a oferta de diferentes satisfações econômicas. Não é suficiente para o negócio fornecer apenas os bens e serviços econômicos; ele os deve fornecer melhores e mais baratos. Um negócio não precisa crescer em tamanho; mas é necessário que constantemente cresça melhorando.

A inovação pode resultar em um preço mais baixo - dado que mais preocupa os economistas, pela simples razão de que ele é o único que pode ser manipulado por ferramentas quantitativas. Mas o resultado pode também ser um produto novo e melhor, uma nova conveniência, ou a definição de uma nova necessidade." (Id., 2007, p. 16-17). Tradução nossa. 
Todas as citações lidam com a questão da inovação dentro da perspectiva da gestão de empresas. Drucker deixa claro que inovar é uma das duas funções, ao lado do marketing, de todo empreendimento empresarial, o qual tem sempre como propósito criar um consumidor, ou seja, estimular certo nível de fidelidade entre os clientes. "Prover diferentes satisfações econômicas" significa, então, ofertar novos e melhores benefícios econômicos, sem se importar somente com o se tornar cada vez maior, mas em tornar-se cada vez melhor. A lógica é clara, bastante explícita. Não basta inovar, por exemplo, lançando um novo produto no mercado por um preço menor que a concorrência. É preciso que tal produto ofereça um diferencial de qualidade, que pode ser expressa na sua durabilidade, levando seu preço a ser maior, mas, na relação final, compensador. Se pensarmos no lançamento dos aparelhos portáteis reprodutores de mídias em formato $\mathrm{mp} 3 \mathrm{e} \mathrm{mp} 4$, o tema fica claro. Existem diferentes marcas no mercado, com preços altamente variados, estando os aparelhos mais baratos frequentemente associados a uma durabilidade menor. Isso nos leva para a citação de Drucker, mais uma vez, quando nos lembra que precisam ser produtos "novos e melhores", pois, ao final, o cliente talvez prefira pagar um pouco mais por um produto que poderá ser utilizado por muito mais tempo.

Simantob nos leva, na citação aqui destacada, para dentro da empresa, sempre lembrando que o fator definidor da inovação em tal ambiente é a obtenção do lucro. Discute a necessidade de se criar um ambiente interno nas empresas voltado ao desenvolvimento de ideias inovadoras. Aqui vale a quantidade: é necessário haver um ambiente que permita criação de numerosas ideias novas, formando um estoque. Dentre todas essas ideias, algumas poucas serão testadas e, outras, em número ainda menor, serão colocadas no mercado. Destas, somente uma parte será uma verdadeira inovação. É tudo mostrado como uma questão de probabilidades. Quanto maior o número de ideias produzidas por uma empresa maior será a possibilidade de que uma delas seja realmente inovadora. Evidente que, em ambientes nos quais as novas ideias são simplesmente repelidas, a inovação jamais acontecerá. Como afirma o mesmo autor: "E para que isso tudo aconteça com eficácia é preciso exercitar os mecanismos, instrumentos e processos da inovação, tornando-os parte das práticas empresariais, incorporando-a ao tecido da organização numa coordenação de ações contínuas." (Idem, 2006a, p. 16).

Diferentes autores discutem como criar o ambiente inovador de que fala Simantob. Uma referência central, discutindo como gerir a produção de conhecimento nas organizações, é o trabalho de Choo (2006), que aponta para a necessidade de investir em meios de socializar os conhecimentos dos funcionários, para, então, criar canais de exteriorização formal dos mesmos, quando podem ser combinados pelos gestores da empresa, desenvolvendo as estratégias para que todos internalizem os novos conhecimentos produzidos. 0 processo descrito por Choo para as empresas é bastante similar ao seguido pelo desenvolvimento do próprio conhecimento científico, que precisa contar com o trabaIho de muitos pesquisadores, socializando suas investigações para se chegar à novas descobertas e realizações (LATOUR, 2000). Podemos, sem nos alongarmos demasiadamente, destacar alguns pontos comuns nos trabalhos que lidam com a temática da inovação. 0 primeiro aspecto sempre ressaltado é justamente a necessidade da criação de um ambiente favorável para o desenvolvimento de novas ideias. Isso significa que a empresa deve ter espaços nos quais tais ideias possam surgir e serem discutidas. Mas não basta tão somente a existência de tal espaço, é preciso que o gerenciamento do mesmo, que é justamente o segundo aspecto ressaltado, proporcione a segurança e o estímulo necessários para a expressão das ideias. Um funcionário amedrontado dificilmente vai expor suas ideias, qualquer que seja o espaço que a empresa disponibilize oficialmente para tanto. Silva nos fala inclusive que é necessária a existência de um clima dentro das organizações favorável ao aparecimento de novas ideias, um ambiente em que as pessoas se sintam confortáveis para tentar. 
Os funcionários precisam ter a liberdade para questionar o que está sendo feito de uma mesma maneira há muito tempo. Isto não é garantia de que as coisas estejam sendo feitas da melhor maneira. Da maneira mais rápida, mais econômica, mais inteligente, mais competitiva. É o talento criativo das pessoas que leva uma empresa a ser admirada como inovadora. Mas só se o clima organizacional permitir. (SILVA, 2002).

Simantob nos lembra, ainda, sobre esse mesmo ponto de Silva: é importante que o funcionário sinta que pode errar em suas iniciativas dentro da empresa, recomendando mesmo que todas sejam recompensadas de alguma forma independentemente dos resultados alcançados: "Os erros devem fazer parte de um aprendizado dentro das organizações que querem inovar. E a premiação desempenha aí um aspecto importante." (SIMANTOB, 2006b). 0 alerta é para o fato de que toda inovação resulta de um trabalho coletivo de construção do conhecimento dentro da organização, que depende da exposição de novas ideias pelos seus funcionários. A punição atribuída para as iniciativas que não forem bem sucedidas é um sinal claro que desestimula a realização da primeira etapa fundamental do processo de criação do conhecimento descrito por Choo: a sua socialização.

É justamente o tema da citação de Bergerman, a terceira apresentada no começo deste artigo, em que se destaca a vinculação entre a inovação e o processo de geração de riquezas para todo o país. É uma consequência lógica do próprio conceito de inovação, com o qual estamos lidando. Um conhecimento somente é classificado como inovador se tiver alcançado resultados econômicos positivos. Entretanto, para que inovação aconteça, são necessárias várias etapas anteriores, muitas tentativas que certamente redundarão em erros. Ainda que tais iniciativas mal sucedidas não possam ser classificadas diretamente como inovações, elas são parte fundamental do processo de produção de conhecimentos, do qual as verdadeiras inovações surgem.

Chegamos, então, a um ponto muito importante do processo aqui em discussão. Para inovar, uma empresa precisa investir muito na criação das condições necessárias para tanto, o que passa por possuir $o$ ambiente adequado, no qual as novas ideias surgem e o capital para testar as que pareçam mais promissoras. É um investimento de risco, fato também apontado suficientemente pela literatura da área. A maioria das ideias que são testadas não se torna realmente inovações, gerando, algumas vezes, prejuízos que a empresa precisa absorver. Tal condição já é um fator desestimulante para as pequenas e, até mesmo, para as médias empresas, que podem ver todo seu capital comprometido pelo fracasso de uma tentativa de inovação. Para as grandes empresas, é mais fácil absorver tais riscos, o que, em muitos casos, já fazem parte da sua previsão de gastos. 0 exemplo da indústria de entretenimento norte-americana é esclarecedor. Os grandes estúdios produtores de seriados televisivos recebem quantidades enormes de roteiros de novos escritores todos os dias. Destes, uma parte será selecionada para avaliação pelos executivos das empresas, que vão, então, escolher alguns para serem filmados, produzindo os chamados "episódios piloto". Somente uma parcela menor desses pilotos será levada ao ar e um número ainda menor será transformado em seriado regular. E, mesmo entre os que se tornarem seriados regulares, somente uma parcela vai alcançar o sucesso necessário para permanecer no ar por alguns anos. É uma indústria fantástica, que produz muito material que jamais será realmente aproveitado, empregando, para isso, uma verba já prevista. Tal investimento é possível, pois o retorno econômico de uma ideia de seriado que realmente funcione será suficiente para cobrir largamente e com muita folga todas as despesas tidas pelo estúdio. É o custo de um ambiente no qual a inovação é certamente central. 0 interessante, no exemplo dos estúdios norte-americanos, é que quanto mais sucesso seus seriados atingirem, mais atrativos eles se tornarão para novos escritores em busca de reconhecimento, como também para os que já tiveram seus nomes consagrados em produções de sucesso. 0 sucesso de uma inovação é um fator que ajuda a atrair novas possibilidades de inovação, como uma redundância inevitável. 0 círculo formado acaba determinando que uma empresa inovadora deve ser inovadora, cada vez mais, pelo menos, se desejar manter sua posição no mercado, enquanto que as que não conseguem inovar ficarão, cada vez mais, restritas em tal posição, até chegarem ao extremo do desaparecimento. Podemos terminar aqui com mais um exemplo significativo do ramo 
televisivo. Nos anos 1990, o seriado Arquivo X (The X Files), criado por Chris Carter, atingiu um sucesso que perdurou por quase uma década, gerando uma franquia enorme de produtos. 0 resultado econômico foi tão grande que Carter conseguiu fundar sua própria produtora, passando a produzir e distribuir seus outros projetos de seriado para a mesma rede televisa. Infelizmente para o roteirista nenhum deles alcançou o sucesso do Arquivo $X$, sendo cancelados sumariamente (o último seriado que produziu teve apenas oito episódios exibidos e nem chegou a ser transmitido em escala mundial). Basicamente, Carter falhou na tentativa de inovar, como havia conseguido realizar com Arquivo X, situação que se agrava, nesse caso, pelos investimentos que realizou na produção dos novos seriados. Hoje, praticamente não se fala mais no seu nome dentro da indústria de seriados de televisão. A trajetória aqui descrita lembra o título de um artigo de Silva (2007): "Crie, inove. Ou evapore".

\section{PENSANDO O CASO BRASILEIRO}

Como fica o Brasil, com sua bagagem histórica, em todo o processo da inovação? Essa é a reflexão central que devemos desenvolver no restante deste artigo. Nós somos responsáveis por cerca de 1,4\% da produção científica mundial (BERGERMAN, 2005), o que, na verdade, chega a ser um dado impressionante, quando nos lembramos das condições gerais de financiamento em nosso país, conforme detalharemos adiante. Mas é também um fato que, quando o assunto é inovação, o Brasil só responde por cerca de $0,1 \%$ do registro de patentes no mundo (Ibid.). Apesar de tal maneira de se medir a inovação, considerando-se somente o registro de novas patentes ser muito questionado em toda literatura, ele nos ajuda a compreender uma parte importante do desenvolvimento do nosso processo de produção de ideias inovadoras. Dados do PINTEC (Pesquisa de Inovação Tecnológica), de 2005, realizado pelo IBGE, nos fornecem um quadro bastante preciso, empregando uma definição de inovação retirada do Manual de Oslo (1997):

A PINTEC segue a recomendação do Manual Oslo, no qual a inovação tecnológica é definida pela implementação de produtos (bens ou serviços) ou processos tecnologicamente novos ou substancialmente aprimorados. A implementação da inovação ocorre quando o produto é introduzido no mercado ou quando o processo passa a ser operado pela empresa. (IBGE, 2005, p. 19).

Seguindo tal definição, vemos reforçado o sentido aqui apresentado de inovação: o que importa é o resultado econômico alcançado com a implementação de um produto ou processo novo para a empresa. Isso ressalta que uma empresa pode inovar constantemente, sem que isso signifique necessariamente que vá introduzir novos produtos no mercado. Ela pode continuar vendendo o mesmo produto de sempre, mas estará inovando cada vez que for capaz de implementar alguma alteração na sua forma de produção que aumente os lucros para a empresa. A pesquisa do PINTEC considera somente empresas regularizadas, cadastradas oficialmente e com mais de 10 pessoas ocupadas em seus quadros. Considerando, então, que é possível inovar sem necessariamente termos um produto novo, o quadro geral nacional, para 2005, revelado pelo PINTEC, é o seguinte:

Tabela 1 - Empresas que investiram em inovação

\begin{tabular}{cccc}
\hline $\begin{array}{c}\text { Total de empresas } \\
\text { analisadas }\end{array}$ & $\begin{array}{c}\text { Inovaram em produto e/ou } \\
\text { processo }\end{array}$ & $\begin{array}{c}\text { Tiveram somente projetos } \\
\text { incompletos e abandonados }\end{array}$ & $\begin{array}{c}\text { Adotaram mudanças estratégicas e } \\
\text { organizacionais }\end{array}$ \\
\hline 95.301 & 32.796 & 2.200 & 34.403 \\
\hline
\end{tabular}

Fonte: PINTEC, 2005.

Não parece tão ruim. Mas o que é realmente revelador aparece quando analisamos as tabelas que indicam de onde vieram as inovações empregadas, ou seja, quem efetivamente produziu a inovação. Aqui, temos o seguinte quadro geral: 
Tabela 2 - Tipo de inovação implementada

\begin{tabular}{ll}
\hline Atividades internas de P\&D* & 6.168 \\
\hline Aquisição externa de P\&D & 1.328 \\
\hline Aquisição de outros conhecimentos externos & 2.767 \\
\hline Aquisição de software & 4.528 \\
\hline Aquisição de máquinas e equipamentos & 17.199 \\
\hline Treinamento & 6.228 \\
\hline Introdução de inovações tecnológicas no mercado & 6.521 \\
\hline Projeto industrial e outras preparações técnicas & 7.346 \\
\hline
\end{tabular}

Fonte: PINTEC, 2005.

*P\&D - Pesquisa e desenvolvimento.

Destaca-se o número reduzido de empresas que atuam gerando conhecimento próprio com $P \& D$. A grande maioria inova adquirindo conhecimentos e equipamentos de fontes externas. Tais dados precisam ser confrontados com os que se seguem, sobre a originalidade dos produtos e/ou processos implementados pelas empresas que inovaram:

Tabela 3 - Originalidade das inovações implementadas

\begin{tabular}{lcc}
\cline { 2 - 3 } Novo para a empresa, mas já existente no mercado nacional & Produto & Processo \\
\hline Novo para o mercado nacional, mas já existente no mercado mundial & 16.345 & 24.658 \\
\hline Novo para o mercado mundial & 3.122 & 1.504 \\
\hline
\end{tabular}

Fonte: PINTEC, 2005.

Os dados destacados, além dos diversos outros disponíveis no PINTEC, nos permitem algumas considerações importantes. 0 que chama atenção, primeiramente, é verificar que, do total de empresas analisadas pelo IBGE (95.301), 62.487 são empresas que possuem de 10 até 29 funcionários, dentre as quais, somente $29,9 \%$ implementaram inovações de produto e/ou processo e $30,6 \%$ não fizeram qualquer tipo de investimento em inovação. Das 1.638 empresas com mais de 500 funcionários, $79,6 \%$ implementaram inovações de produto e/ou processo, enquanto apenas $6,3 \%$ não fizeram qualquer tipo de investimento em inovação. Tais informações ajudam a corroborar um dos argumentos aqui já apresentados, de que o processo de inovação depende grandemente da capacidade de investimento da empresa, envolvendo, portanto, sua capacidade de assumir riscos econômicos. Aqui, temos um ponto a ser lembrado: o investimento em inovação é visto como um risco e, sendo assim, pode aparecer como algo que precisa ser sempre minimizado, principalmente para empresas de menor porte, conforme afirmado anteriormente.

Destaca-se também, dos dados apresentados, que a maioria das empresas que inovaram em produto e/ou processo enquadram-se no item "novo para a empresa, mas já existente no mercado nacional". Tal item revela que a maior parte das empresas adotam inovações somente quando já estão comprovadas pelo desempenho das empresas líderes no mercado, confirmando a fuga dos riscos. Até aqui, não estamos fazendo uma grande revelação. Precisamos visualizar que o problema é que a postura adotada, de buscar somente por inovações que já estão testadas, indica que a disposição geral para estimular inovações no meio empresarial nacional ainda é baixa. Tal postura segue paralela com as informações sobre a aquisição das inovações, que nos revela que a grande maioria busca por 
fontes de inovação externas à empresa, como pode ser visto no item sobre a aquisição de máquinas e equipamentos da Tabela 2. Tais pontos são também confirmados por pesquisa de Rocha e Ferreira (2001), ao compararem o desempenho das empresas privatizadas com um grupo geral de empresas no Brasil, no que se refere aos investimentos em inovação. Os autores destacaram que houve diminuição dos investimentos em P\&D nas empresas privatizadas.

\begin{abstract}
No que se refere às atividades inovadoras, registra-se queda da importância relativa dos gastos com "P\&D" para o Grupo de Empresas Privatizadas (em 1994 estes gastos correspondiam a 68,4\% do investimento total em inovação, tendo crescido para $65,0 \%$ em 1998), simultaneamente a um vertiginoso crescimento da participação relativa da categoria "aquisição de tecnologia" (este item que representava $5,2 \%$ do investimento total em inovação no primeiro ano da série, elevou-se para 13,1\% em 1998) [...]. Este resultado sugere uma tendência de aumento da compra de tecnologia (sob a forma de pagamentos de assistência técnica e de uso de marcas e patentes), em detrimento dos esforços de geração autônoma por parte das empresas privatizadas. (ROCHA; FERREIRA, 2001, p. 66-67).
\end{abstract}

Por esses e outros motivos é que Plonsky sugeriu, em um artigo de 2005, o estabelecimento de um Movimento pela Inovação Tecnológica (PLONSKY, 2005, p. 27).

Todas essas informações nos ajudam a entender por que as pesquisas em novas tecnologias estão restritas, no Brasil, às universidades, onde contam com o patrocínio público para serem realizadas, enquanto no exterior a realidade é oposta. Segundo Bergerman

\begin{abstract}
quem faz inovação no mundo? [...] Várias instituições, mas majoritariamente o setor privado. Nos países desenvolvidos é o setor privado quem realiza a inovação - contratando milhares de cientistas e engenheiros, financiando seus próprios laboratórios corporativos de P\&D (15.000 nos EUA, 5.000 na Coréia do Sul) e protegendo suas inovações por meio de registros de propriedade intelectual (patentes, registros de software, marcas, etc.). Interessante e importante é notar que a atividade de inovação nestes países deve-se em grande parte à maciça presença de doutores (e cientistas em geral) nas empresas, enquanto no Brasil a maioria destes profissionais atua em universidades. (BERGERMAN, 2005, p. 1335).
\end{abstract}

Segundos dados do mesmo autor, nos EUA, $72 \%$ dos engenheiros e cientistas atuam no setor privado, enquanto, no Brasil, esse número cai para $23 \%$. Claro que tais números indicam a óbvia concentração das grandes empresas nos países mais desenvolvidos, mas revelam, principalmente, diferentes políticas no que se refere à $P \& D$, que possuem relações com uma outra série de dados fundamentais. Esses vão dizer respeito a quem somos enquanto nação, trazendo uma contribuição mais direta da sociologia e das ciências sociais, em geral, para a temática da inovação.

O SIR (Scimago Institutions Rankings) publicou o Ranking Iberoamericano SIR 2010, revelando a continuidade do mesmo quadro. Foi investigada a produção científica das universidades dos países ibero-americanos, levando-se em consideração não somente a quantidade de textos publicados, mas também a qualidade e a relevância dos mesmos, através da identificação do número de referências feitas aos mesmos em outras publicações registradas no índice Scopus-Elsevier. A pesquisa avaliou a produção feita entre os anos de 2003 e 2008, com resultados extremados mais do que reveladores. Em primeiro lugar no ranking, aparece a Universidade de São Paulo-USP, com um total de 37.952 publicações; em segundo, temos a Universidade Nacional Autônoma do México, com 17.395 publicações e, em terceiro, a Universidade Estadual de Campinas-UNICAMP, com 14.913. Na classificação geral por países, ficamos em segundo lugar, com 178.765 publicações, atrás da Espanha, com 208.078. Figuram, ainda, a Universidade Estadual Paulista Júlio de Mesquita Filho-UNESP (12.270 publicações) e a Universidade Federal do Rio de Janeiro-UFRJ (12.133 publicações), simultaneamente em sexto e sétimo lugares. A primeira universidade privada brasileira que aparece no ranking ocupa a posição 73 , com um total de 2.173 publicações científicas. Entre a colocação das universidades públicas, aqui já mencionadas, e a dessa universidade particular, temos ainda outras três universidades estaduais e mais doze universidades federais (tais como a Universidade de Brasília-UnB, a Universidade do Estado do Rio de Janeiro-UERJ e a Universidade Federal de Minas Gerais-UFMG). O ranking segue até a posição 607, 
sendo que as 17 últimas universidades apresentaram apenas um artigo em todo o período analisado. A diferença na quantidade de publicações é enorme e reflete muito do que já foi aqui afırmado sobre a concentração da pesquisa científica brasileira nas universidades públicas. Novamente, reafirma-se que precisamos entender com mais cuidado os elementos definidores desse quadro da P\&D no Brasil.

\section{SOCIEDADE E INOVAÇÃO}

Diversos foram os autores, dentro das Ciências Sociais, que se dedicaram a tentar decifrar o que se costumava chamar de ethos do brasileiro, ou seja, quem somos nós, o que nos torna brasileiros, diferenciando-nos dos outros povos. Não cabe, nos propósitos deste artigo, uma revisão completa de tal literatura e, por isso, a opção adotada foi a de concentrar a reflexão nos textos clássicos de tal temática. Tais textos trazem contribuições à reflexão sobre quem somos que foram incorporadas por diferentes pensadores e pesquisadores, não somente do mundo acadêmico das ciências sociais. Aqui irei trabalhar com um recorte considerado clássico, abordando os trabalhos de Gilberto Freyre e Sérgio Buarque de Holanda, sobre a questão do nosso ethos; Raymundo Faoro, na questão das nossas estruturas de poder; e Celso Furtado, em quem buscarei uma análise mais voltada para o plano da economia.

A preocupação de Holanda, ao escrever sua obra Raízes do Brasil, era a de contribuir para a reflexão sobre o ethos nacional, que, em sua época, era fortemente marcada pelas reflexões de Gilberto Freyre, apresentadas no clássico Casa-Grande \& Senzala. A interpretação de Holanda difere radicalmente da de Freyre. No último, a sociedade brasileira é descrita partindo de um olhar que sai da casa-grande em direção da senzala, ou seja, uma visão elitista da nossa realidade. A obra de Freyre, marcada por descrições que remontam ao tempo de infância do próprio autor, ficou famosa por apresentar a tese de que o Brasil viveria em uma democracia racial. A ideia é de que as relações estabelecidas entre os senhores e demais moradores da casa-grande com os escravos que habitavam as senzalas seria determinante para o nosso modo de ser. Freyre nos apresenta uma sociedade na qual a escravidão seria muito mais amena que em outras partes do mundo. Tal fato teria acontecido por conta das relações de intimidade sexual que foram estabelecidas entre os senhores e suas escravas, gerando uma camada de mestiços que, se não eram tratados como filhos legítimos, também não teriam sido tratados como escravos. Na descrição de Freyre, a violência da escravidão desaparece, pois foi amenizada pelas relações familiares que marcam a estrutura de funcionamento das casas-grandes. As características mais evidentes do brasileiro, de buscar proximidade imediata com qualquer pessoa, de tratar autoridades sem qualquer tipo de formalidade, de empregar abusivamente os diminutivos seriam traços de um caráter geral moldado no contato direto entre brancos livres e negros escravos, um sinal da proximidade entre classes e raças, de nossa suposta democracia racial. Na verdade, é possível ler o livro inteiro sem se dar quase conta de que o autor está falando de uma relação de dominação direta, na qual o dominado não é simplesmente subjugado, mas é coisificado, transformado em mercadoria. Freyre era influenciado por uma falsa impressão de que, no Brasil, não existiriam confrontos entre as raças, as quais teriam estabelecido relações harmoniosas entre si por conta da maleabilidade das relações sociais estabelecidas em torna da casa-grande.

É uma tese polêmica, mas que prevaleceu por muito tempo, ainda ressurgindo cada vez que a nossa miscigenação é levantada como argumento para afırmar que, no Brasil, não existem conflitos raciais. $\mathrm{Na}$ tese de Freyre, o indivíduo miscigenado, principalmente da mistura entre o branco e o negro, aparece como o protótipo do brasileiro. Fica completamente de fora, da discussão desse autor, as relações de dominação, inclusive sexual, dos senhores brancos sobre suas escravas negras. Na verdade, tais relações são apresentadas como se fossem resultados de casos amorosos consentidos, esquecendo-se que o objeto, a mercadoria, como eram considerados os escravos, não pode, por definição, consentir em nada. Objetos existem para serem utilizados por seus proprietários. Contudo, cumpre lembrar que 
a análise de Freyre foi extremamente importante ao combater a noção de eugenia, em voga no início do século XX, e que culminaria no nazismo alemão da II Guerra Mundial (1939-1945). Em tal contexto, Freyre procurou mostrar que não havia relação nenhuma de inferioridade "natural" entre brancos e negros, tendo contribuído, ambos, igualmente para a formação do povo brasileiro.

Em Holanda, temos uma perspectiva muito diferente. O foco de sua reflexão encontra-se no conceito de homem cordial, que seria a definição máxima do ethos nacional. Holanda analisa as mesmas relações de patriarcalismo em nossa sociedade, ressaltadas por Freyre, fundamentadas na existência de uma classe dominante que havia transferido a lógica da organização familiar para o controle do Estado. Vejamos com mais cuidado, pois esse é um ponto importante para a continuidade da reflexão proposta sobre a inovação. Holanda descreve a organização das famílias dos grandes senhores de terras, organizadas ao redor da autoridade e da vontade do pai, o patriarca, que define os rumos da vida de todos que dele dependem. Aos demais familiares e dependentes cabia a obediência. Tais senhores e suas famílias compunham o topo da elite nacional, ocupando todos os altos cargos de comando, configurando um Estado patrimonialista, ou seja, que era visto como parte do patrimônio pessoal desses senhores, podendo ser transmitido diretamente a seus descendentes. Para o restante da população, não sobravam muitas opções: ou se submetiam à autoridade patrimonial, ou então, ficavam excluídas de todas as possibilidades de acesso que deveriam ser seus direitos fundamentais de cidadão. É aqui que aparece o conceito de homem cordial de Holanda, e que Victor Nunes Leal descreveu na sua obra Coronelismo, enxada e voto (1975).

A ideia de cordialidade em Holanda pressupõe, inicialmente, o sentido comum da palavra. É a descrição do brasileiro como um povo acolhedor, que procura sempre tratar a todos com muita proximidade, que não gosta dos rituais sociais rígidos, muito parecida com a construção do ethos nacional feita por Freyre. Mas Holanda vai além das aparências. Ele mostra que tal cordialidade serve somente para esconder uma realidade excludente. Nossa sociedade é dominada por uma elite que trata o Estado e tudo que é público como se fosse parte de seu patrimônio pessoal, procurando passar cargos políticos quase em uma relação direta de hereditariedade. Nesse contexto geral, não há espaço para a mobilidade social baseada em capacitação e mérito pessoal. Somente vão chegar aos postos mais altos, ou até mesmo aos de mais baixo escalão hierárquico, as pessoas que conseguirem participar, de alguma maneira, da esfera de influência de algum senhor poderoso. Daí a necessidade de cordialidade: é preciso tratar todos, principalmente às figuras de autoridade, como se fossem nossos amigos íntimos, construindo uma relação fundamentada na troca de favores. A cordialidade nacional seria, então, somente mera aparência, uma máscara que as pessoas utilizam para amenizarem relações sociais que são, na verdade, extremamente desiguais.

Outro autor, Raymundo Faoro, descreveu tal classe dominante, no Brasil, como "os donos do poder", uma elite nacional que sempre esteve no comando do Estado e da economia, desde os tempos da colônia. Tal elite vem passando adiante seu poder no Brasil para seus próprios herdeiros, quer seja através da ocupação de cargos políticos, como pelo controle das estruturas econômicas.

Mas, em que ponto tudo isso vai se relacionar com a discussão sobre a inovação? Em outras palavras, como tais reflexões sociológicas podem servir para a melhor compreensão da temática da necessidade de inovação dentro do quadro geral das empresas no Brasil?

Vamos começar retomando o último ponto tratado sobre a inovação, de que, no Brasil, as pesquisas relacionadas com o desenvolvimento de novas tecnologias estão concentradas nas universidades, principalmente nas grandes universidades públicas. Tal realidade indica muito mais do que somente a distância efetivamente existente entre as empresas e as universidades, mas os efeitos perversos de um sistema patrimonialista de governo que ainda persiste, de certo modo, em nosso país. Nesse sentido, 
fica fortemente sugerido que nossas elites continuam tratando os assuntos relativos à condução do Estado como uma extensão de seus interesses pessoais. Não realizam os altos investimentos diretos em pesquisas que gerem inovações em suas empresas, deixando que o Estado, ou seja, que toda a sociedade arque com tais despesas. Se isso é feito de maneira absolutamente intencional ou se é o resultado de uma dinâmica mais ampla e até mesmo involuntária é algo a ser investigado, mas cujos efeitos práticos para os fins da análise aqui proposta são os mesmos. Celso Furtado (1968) já definiu tal processo, em um contexto histórico mais geral, como uma socialização das perdas, ou seja, tornar coletivos prejuízos que deveriam ser pessoais, enquanto que os lucros, quando se realizam, são aproveitados privadamente. Foi o mecanismo empregado, segundo Furtado, para superar os efeitos da crise da exportação do café, nas primeiras décadas do século XX: "Como as importações eram pagas pela coletividade em seu conjunto, os empresários exportadores estavam, na realidade, logrando socializar as perdas que os mecanismos econômicos tendiam a concentrar em seus lucros." (FURTADO, 1968, p. 174). Um exemplo de tal prática foi o chamado Convênio de Taubaté, durante o período classificado na historiografia nacional como República Oligárquica (do final do século XIX até 1930), pelo qual o governo federal, apesar de ter demonstrado inicialmente resistência, comprometeu-se a comprar toda a produção de café que os poderosos cafeicultores de São Paulo, Minas Gerais e Rio de Janeiro não tivessem conseguido vender, realizando empréstimos no exterior para cobrir tais gastos. Foi a solução encontrada pelos grandes fazendeiros, que dominavam toda a política nacional, para superaram as dificuldades da concorrência estrangeira na produção do café, que havia provocado uma queda geral do preço da sua saca no mercado internacional. Assim, garantiam-se os lucros de uma parcela de nossas elites, à custa do sacrifício de toda população, que continuava a ter seu trabalho explorado. Interessante lembrar que tal sistema econômico de valorização do café acabou sendo rompido somente por conta dos efeitos da crise mundial de 1929 e de um processo revolucionário, a Revolução de 1930, a qual conduziu o país aos quinze anos de governo de Getúlio Vargas, vividos em boa parte sob a ditadura do Estado Novo.

Os estudos sobre o papel de nossas elites na condução do Estado precisam, então, ser aprofundados, pois a influência que exercem na definição das políticas públicas é grande, ainda que não seja a única e, muitas vezes, nem mesmo a definitiva. É como nos fala Reis:

Reconhecer a importância das elites também não significa negar a importância dos demais atores sociais. 0 comportamento das elites é, em grande parte, reativo às pressões e ações vindas de baixo. Como quer que seja, a maneira como as elites reagem, suas ações e inações são aspectos centrais quando se quer entender a dinâmica das desigualdades e/ou identificar maneiras de combater a pobreza e reduzir as desigualdades. (REIS, 2000, p. 488)

\section{CONSIDERAÇÕES FINAIS}

As reflexões apresentadas neste artigo não pretendem ser definitivas, possuindo um caráter exploratório e introdutório para algumas possibilidades de contribuição das Ciências Sociais às reflexões sobre a questão da inovação. Apesar de parte da literatura dedicada ao tema apontar para uma vinculação direta da noção de inovação com a obtenção de um resultado econômico positivo, a discussão remete diretamente para a questão da produção das pesquisas científicas, pois, mesmo considerando que uma inovação pode ser qualquer alteração em um processo produtivo que diminua os gastos de uma empresa, é inegável que as inovações que geram os maiores lucros estão relacionadas com novas descobertas científicas que possuam aplicabilidade de mercado. E a produção desses conhecimentos possui um custo. Podemos pensar aqui no desenvolvimento do Iphone pela Apple, um aparelho que revolucionou o mercado de telefonia celular, justamente ao inovar no modo como o usuário interage com o aparelho. Mas a inovação não parou na produção do aparelho, sendo necessário mencionar também o desenvolvimento da loja virtual da Apple, que vende aplicativos exclusivos para o aparelho, 
como jogos em 3D, leitores de notícias, editores de texto, escâneres e tudo mais que os programadores puderem imaginar. Trata-se de uma ótima maneira de incrementar os lucros sem incorrer em grandes gastos, já que outras empresas e programadores individuais podem apresentar seus aplicativos para serem avaliados pela Apple e, se aprovados, colocados à venda. Por esse aspecto, a própria loja virtual se torna um espaço para o teste prático dos novos aplicativos para o Iphone, contando com um espaço reservado para que os usuários postem suas opiniões, sugestões e reclamações.

Vimos que, no Brasil, é essencialmente o poder público, através das universidades estaduais e federais, quem tem financiado o desenvolvimento das pesquisas científicas que depois poderão ser utilizadas pelas nossas empresas. Pesquisa feita por Cruz e Nagano (2008), em dois parques tecnológicos do estado de São Paulo, na região de Campinas e de São Carlos, revelou o seguinte sobre essas empresas:

Tratam-se de empresas que estão constantemente inovando, formadas em sua maioria por pessoas altamente
especializadas em sua área de atuação; ademais há transferências continua de conhecimento universidades-
-empresas devido ao contexto em que estão inseridas. (CRUZ; NAGANO, 2008, p. 90)

Nas duas regiões, temos a presença de universidade públicas: uma em Campinas (a UNICAMP) e duas em São Carlos (um campus da USP dedicado, basicamente, às ciências exatas e a Universidade Federal de São Carlos-UFSCAR). São as universidades que ocupam o terceiro e o primeiro lugar no ranking do SIR anteriormente comentado. Os parques tecnológicos analisados pelos autores contam também com a presença de várias universidades e faculdades privadas, de porte diverso. Considerando todas juntas, temos duas regiões onde a presença de mão-de-obra qualificada é, praticamente, uma certeza. Mas, mesmo considerando-se que as empresas que compõem esses dois parques investem também em inovação, elas contam com a transferência direta dos conhecimentos produzidos nas universidades, realizado tanto através da contratação dos recém-formados, como no desenvolvimento de parcerias diversas de pesquisa.

Cabe ainda observar, no que se refere ao fato de que os nossos pesquisadores qualificados, com nível de Doutorado, encontram-se majoritariamente nas universidades, contrariamente ao que ocorre em países como os EUA, a existência da questão do vínculo empregatício estável. 0 trabalho em uma universidade pública garante uma estabilidade financeira, que mesmo não sendo a ideal, permite a continuidade das atividades de pesquisa. A insegurança encontrada no trabalho em empresas privadas, ainda que com uma remuneração maior, também exerce um papel que precisa ser mais bem investigado. Mas, mesmo que o impacto de tal situação seja considerado, não serve para explicar, sozinho, a concentração das pesquisas científicas em nossas universidades, sendo necessário considerar os elementos ressaltados ao longo deste artigo e tantos outros mais que puderem ser elencados.

Evidente que os argumentos aqui destacados não excluem a existência de empresas que investem efetivamente em P\&D no Brasil, ajudando a compor a nossa participação geral no índice mundial, conforme afirma Bergerman (2005). Mas as pesquisas indicam, invariavelmente, que a participação das universidades públicas é sempre fundamental, como no trabalho conduzido pelo Instituto Inovação (MOREIRA et al, 2007), que destaca as regiões com potencial maior para a produção de conhecimentos que gerem inovações. São justamente as cidades que têm uma quantidade grande de mestres e doutores, os quais trabalham em grandes centros universitários, conjugando, portanto, qualidade e quantidade. Ao mesmo tempo, trabalhos como o de Pereira e Muniz (2006) ressaltam as dificuldades de nossas universidades em conseguir gerenciar a produção de inovações, principalmente no que se refere ao registro de novas patentes.

Para finalizar, podemos dizer, em suma que, na medida em que as universidades continuarem a serem os principais centros de pesquisa para o desenvolvimento de novas tecnologias no país, estaremos atuando dentro da mesma antiga lógica, de deixar a encargo do Estado a responsabilidade 
pelos investimentos de risco e de implementação de setores estratégicos da economia. Nada disso representará qualquer transformação para nossa população, se tais investimentos, pagos por ela, não vierem acompanhados da mais do que necessária justiça social, principalmente no que se refere à participação de todos nos resultados positivos dos investimentos que ajudamos a financiar.

\section{REFERÊNCIAS}

BERGERMAN, Marcel. Inovação como instrumento de geração de riqueza no Brasil. Parcerias Estratégicas, n.20, jun. 2005. Disponível em: <http://www.cgee.org.br/parcerias/p20.php>. Acesso em out. 2007.

CHOO, Chun Wei. A Organização do Conhecimento - Como as organizações usam a informação para criar significado, construir conhecimento e tomar decisões. 2.ed. São Paulo: Senac, 2006.

CRUZ, Claúdia Andressa, NAGANO, Marcelo Seido. Gestão do conhecimento e sistemas de informação: uma análise sob a ótica da teoria da criação do conhecimento. Perspectivas em Ciências da Informação, v.13, n.02, p. 88-106, mai/ago. 2008.

DRUCKER. Peter F.. The Essential Drucker. Oxford: Elsevier Ltd., 2007.

The New Realities. New Jersey: Transaction Publishers, 2009.

FAORO, Raymundo. Os Donos do Poder - Formação do patronato político brasileiro. 10.ed., São Paulo: Globo/Publifolha, 2000. (v. 1).

Os Donos do Poder - Formação do patronato político brasileiro. 10.ed., São Paulo: Globo/ Publifolha, 2000. (v. 2).

FREYRE, Gilberto. Casa-grande \& Senzala. 31.ed. Rio de Janeiro: Record, 1996.

FURTADO, Celso. Formação Econômica do Brasil. 8.ed., São Paulo: Editora Nacional, 1968.

HOLANDA, Sérgio Buarque de. Raízes do Brasil. 26. ed. São Paulo: Companhia das Letras, 1995.

IBGE - INSTITUTO BRASILEIRO DE GEOGRAFIA E ESTATíSTICA. Censo Demográfico. Disponível em: $<$ http://www.ibge.gov.br/>. Acesso em 20 nov. 2005.

Pesquisa de Inovação Tecnológica (PINTEC) -2005. Disponível em: <http://www.ibge.gov.br/ home/estatistica/economia/industria/pintec/2005/default.shtm>. Acesso em: out. 2007.

KURZ, Robert. As luzes do mercado se apagam: as falsas promessas do neoliberalismo ao término de um século em crise. Estudos Avançados, São Paulo: maio/ago. 1993.

LATOUR, Bruno. Ciência em Ação - Como seguir cientistas e engenheiros sociedade afora. São Paulo: Editora UNESP, 2000.

LEAL, Victor Nunes. Coronelismo, enxada e voto. 2.ed., São Paulo: Alfa-Omega, 1975.

MOREIRA, Bruno et al. Onde está a inovação no Brasil?. Instituto Inovação, 2007. Disponível em: <http:// www.scribd.com/doc/3473041/Onde-esta-a-inovacao-no-Brasil-2007>. Acesso em: 16 jun. 2010. 
PEREIRA, L. B., MUNIZ, R. M.. Obstáculos à Inovação: um estudo sobre a geração de spin-offs universitárias na realidade brasileira. XXIV Simpósio de Gestão da Inovação Tecnológica, Gramado 2006. Disponível em: <http://www.institutoinovacao.com.br/internas/artigo/idioma/1/46/Obstaculos+a+Inovacao-+um +estudo+sobre+a+geracao+de+spin-offs+universitarias+no+Brasil>. Acesso em: 16 jun. 2010.

PLONSKI, Guilherme Ary. Bases para um movimento pela inovação tecnológica no Brasil. São Paulo em Perspectiva, jan/mar 2005.

REIS, E. P.. Percepções da elite sobre pobreza e desigualdade. In: Desigualdade e Pobreza no Brasil, IPEA, 2000.

ROCHA, Elisa Maria Pinto da, FERREIRA, Marta Araújo Tavares. Análise dos indicadores de inovação tecnológica no Brasil: comparação entre um grupo de empresas privatizadas e o grupo geral de empresas. Ci. Inf. [online]. 2001, vol.30, n.2, pp. 64-69.

SCIMAGO INSTITUTIONS RANKINGS. Ranking Iberoamericano SIR 2010. 2010. Disponível em: <http:// www.scimagoir.com/>. Acesso em: 15 jun. 2010.

SILVA, Antonio Carlos Teixeira da. Pense Diferente. 2002. Disponível em: <http://www.novomilenio.inf. br/ano02/0201c013.htm>. Acesso em: 11 jun. 2010.

Crie, inove. Ou evapore. RH Portal. Set. 2007. Disponível em: <http://www.rhportal.com.br/ artigos/wmview.php?idc_cad=88fagz7a5>. Acesso em: 11 jun. 2010.

SIMANTOB, Moysés. Caracterização de Processos Sistemáticos e Assistemáticos de Inovação em Organizações Brasileiras. 2006a. Dissertação (Mestrado em Administração de Empresas)-Fundação Getúlio Vargas, Escola de Administração de Empresas de São Paulo, São Paulo, 2006a.

0 brasileiro só sabe imitar. Assintecal, 2006b. Disponível em: <http://www.administradores. com.br/informe-se/informativo/moyses-simantob-o-brasileiro-so-sabe-imitar/5971/>. Acesso em: 11 jun. 2010. 